\title{
Potassium dithionate EPR dosimetry for determination of absorbed dose and LET distributions in different radiation qualities
}

Håkan Gustafsson, Anders Lund and Eva Lund

\section{Linköping University Post Print}

N.B.: When citing this work, cite the original article.

Original Publication:

Håkan Gustafsson, Anders Lund and Eva Lund, Potassium dithionate EPR dosimetry for determination of absorbed dose and LET distributions in different radiation qualities, 2011, Radiation Measurements, (46), 9, 936-940.

http://dx.doi.org/10.1016/j.radmeas.2011.03.006

Copyright: Elsevier http://www.elsevier.com/

Postprint available at: Linköping University Electronic Press

http://urn.kb.se/resolve?urn=urn:nbn:se:liu:diva-12964 
Potassium dithionate EPR dosimetry for determination of absorbed dose and LET distributions in different radiation qualities.

Håkan Gustafsson ${ }^{*}$, Anders Lund ${ }^{2}$ and Eva Lund ${ }^{1}$

1 Department of Medical and Health Sciences (IMH), Radiological Sciences, Linköping University, 58185 Linköping, Sweden

2 Department of Physics Chemistry and Biology, Linköping University, 58183

Linköping, Sweden

Corresponding author: Håkan Gustafsson, Department of Medical and Health

Sciences (IMH), Radiological Sciences, Linköping University, 58185 Linköping,

Sweden

Phone: +46 0101031475

Fax : -

E-mail: hakan.l.gustafsson@liu.se 


\begin{abstract}
With an increasing interest in using protons and light ions for radiation therapy there is a need for possibilities to simultaneously determine both absorbed dose $(D)$ and linear energy transfer, LET, $\left(L_{\Delta}\right)$. Potassium dithionate $\left(\mathrm{K}_{2} \mathrm{~S}_{2} \mathrm{O}_{6}\right)$ tablets were irradiated in a conventional 6 MV linear accelerator photon beam and a $\mathrm{N}^{7+}$ beam $(\mathrm{E}=33.5 \mathrm{MeV} / \mathrm{u})$ respectively. The EPR spectrum of irradiated potassium dithionate is a narrow doublet consisting of two signals, $R_{1}$ and $R_{2}$, with different microwave power saturation properties. On the basis of identification in related substances by EPR and ENDOR, these two signals are assigned to two nonequivalent $\mathrm{SO}_{3}{ }^{-}$-radicals. Our experiments showed that the ratios of these two lines $\left(R_{1} / R_{2}\right)$ were clearly connected to beam LET. Irrespective of the mechanistic details this investigation suggests a new method for measurement of absorbed dose and beam LET by using potassium dithionate EPR dosimetry.
\end{abstract}

Keywords: EPR dosimetry, linear energy transfer, LET, charged particles. 


\section{Introduction}

Radiation induced radicals are often very stable in crystalline solid materials. These radicals can be detected and quantified by means of electron paramagnetic resonance, EPR. The signal intensity is proportional to the concentration of paramagnetic species (at least up to $\mathrm{kGy}$ doses) and is therefore also proportional to the absorbed dose. Polycrystalline alanine has been used for EPR dosimetry since more than 25 years (Regulla and Deffner 1982) but suffers from low sensitivity for routine applications in radiation therapy. A number of more sensitive dosimeter materials (e. g. salts of formic acid and dithionic acid salts) has therefore been proposed and some of them has been tested for measurements of low doses with enhanced precision (Lund et al. 2002, Gustafsson et al. 2004). The currently most promising material is lithium formate monohydrate (Gustafsson et al. 2008a, Antonovic et al. 2009, Adolfsson et al. 2010, Waldeland et al. 2010a and Waldeland et al. 2010b). It is two to six times more sensitive than alanine depending on the read-out procedure and has a simple, single - lined, EPR spectrum. Dithionates are another proposed type of EPR dosimeter materials that are even more sensitive than lithium formate monohydrate and with remarkable narrow EPR line widths and stable EPR signals due to the irradiation induced cleavage of the S-S bond of the $\mathrm{S}_{2} \mathrm{O}_{6}{ }^{2-}$ ion (Bogushevich and Ugolev 2000, Lund et al. 2002, Danilczuk et al. 2008, Gustafsson et al. 2008b). The radical yield can in some cases be further enhanced by transition metal dopants (Gustafsson et al. 2005). The far most intense absorption line has been identified as due to $\mathrm{SO}_{3}{ }^{-}$anion radicals in some cases stabilized at two inequivalent sites (Baran et al. 2006, 2007, 2008). This is similar to the radical formation observed in irradiated caesium dithionate (Mahgoub et al. 1983, 1994).

Several EPR studies have shown that the yield of stable paramagnetic species, for a constant absorbed dose, depends on the linear energy transfer (LET) of the radiation. The yield of radicals and thus the EPR signal intensity is decreasing with increasing LET (e. g. Hansen and Olsen 1989, Olsson et al. 2000, Waldeland et al. 2010b). For determinations of absorbed dose in high-LET radiation fields using EPR dosimetry, the LET-dependence must be taken 
into account. For accurate dose determinations the calibration of the dosimeters must either be performed in beams with the same LET as the beam in which the dosimeters are going to be used, or otherwise the signal intensity in the dosimeters must be multiplied with a correction factor to compensate for the differences in radical yield depending on differences in LET between irradiation of calibration tablets and dosimeters.

Ciesielski and Wielopolski (1994) and Ciesielski et al. (1998) have shown that the shape of the EPR spectrum of irradiated alanine depends on the beam quality. In addition to an increased peak to peak height with increasing absorbed dose, they observed a radiation quality dependent change in the relative ratio of two peaks in the alanine spectrum. ENDOR studies have shown that the alanine spectrum consists of the signals from at least three radicals (Sagstuen et al. (1997)). The increased temperature expected in the heavy charged particle tracks (Norman (1967)) might induce changes in the relative amounts of radicals in irradiated alanine, detected as slight changes in the relative ratio of EPR lines in the alanine spectra. However, as pointed out by Malinen et al. (2006), the underlying mechanisms need to be further studied.

Heavy charged particles ionize the irradiated matter more densely along the particle tracks, probably resulting in an increased local radical concentration. It is therefore expected that irradiation with heavy particles also has an influence on the phase memory time, $T_{m}$. For purely homogenously broadened EPR signals this is expected to be seen as increased EPR line widths for samples irradiated with heavy particles as compared to photon irradiated samples. However, it should be noted that changes in $T_{m}$ may not significantly change the line widths of EPR signals broadened by unresolved hyperfine couplings, i.e. inhomogeneous broadened EPR signals. In literature it has been reported that lithium formate irradiated with neutrons (Malinen et al. 2006) and protons and nitrogen ions (Waldeland et al. 2010b) have a slightly increased line width as compared to samples irradiated with photons. Rakvin et al. (2007) observed a change in $T_{m}$ using pulsed EPR methods in alanine irradiated with 
different ions as compared to photon irradiated samples. Ciesielski and Wielopolski (1994) did however not observe an increased line width after irradiation with heavy charged particles (but they observed an increased line width for high doses above $10 \mathrm{kGy}$ regardless of radiation quality). They concluded that there was no substantial increase in local radical concentration in alanine irradiated with heavy particles as compared to low-LET-irradiation. Recently Marrale et al. (2009) used pulsed EPR methods to measure radical distributions in ammonium tartrate exposed to radiation with different LET. They found experimental evidence that the radical distributions are indeed dependent on radiation LET. Several investigators (Ciesielski and Wielopolski (1994), Ciesielski et al. (1998), Malinen et al. (2006)) report changes in the power saturation properties of material irradiated with high LET as compared to photon irradiated samples indicating that high-LET irradiation may alter the crystal lattice and therefore the spin-lattice relaxation time $T 1$.

Potassium dithionate dosimeters irradiated by heavy charged particles $\left(\mathrm{C}^{6+}\right.$ and $\mathrm{N}^{7+}$ ) have recently been studied using EPR imaging (Gustafsson et al. (2008b)). It was shown that the EPR spectrum of potassium dithionate is a narrow doublet (total width approximately 0.5 $\mathrm{mT}$ ) consisting of two signals, $R_{1}$ and $R_{2}$ with different microwave power saturation properties. In addition to the possibility to use the peak-to-peak amplitude $\left(R_{1}+R_{2}\right)$ for measurements of absorbed dose, there were also indications that the relative ratio of the two signals, $R_{1}$ and $R_{2}$, depended on beam LET. The aim of the present investigation is to further study this relation between the relative ratio of the two signals, $R_{1}$ and $R_{2}$ and different beam LET. As shown below, this ratio could indeed be quantified and the presented work therefore suggests a new method for measurement of absorbed dose and beam LET by using potassium dithionate EPR dosimetry. 
2. Materials and methods

2.1. Chemicals and sample preparation

Potassium dithionate was synthesised according to the standard literature (Brauer 1954) at the Department of Materials Chemistry, Uppsala University, Sweden. Solid household paraffin (100 \% by weight, Haugen-Gruppen $\mathrm{AB}$ ) was used as a binder.

Polycrystalline potassium dithionate was crushed in a mortar and sieved to grain size interval $180<\mathrm{d}<500 \mu \mathrm{m}$ using an Endecotts MINOR test sieve shaker. The material was heated with $10 \%$ paraffin until the paraffin had melted. The temperature was always well below the melting point for potassium dithionate. The mixture consisting of potassium dithionate and liquefied paraffin was thoroughly mixed while cooling to room temperature. Melting and mixing was repeated three times in order to produce a homogeneous mixture. Finally the mixture was kept in room temperature until the paraffin had solidified completely and was thoroughly mixed a last time. Tablets (diameter $4.5 \mathrm{~mm}$, length $5 \mathrm{~mm}$, weight $170 \mathrm{mg}$ ) were pressed using a manual tablet press. The mass difference between the tablets was less than $\pm 2 \mathrm{mg}$.

\subsection{Irradiations}

Photon irradiations were performed using a Varian Clinac C/D 6 MV linear accelerator. Doses were measured as absorbed dose in water using an ionisation chamber of type RK 83o5 traceable to the primary standard dosimetry laboratory BIPM in Paris. Tablets were irradiated in a $15 \mathrm{~cm} \cdot 15 \mathrm{~cm}$ radiation field at $5 \mathrm{~cm}$ depth in a PMMA slab phantom using a dose rate of $3 \mathrm{~Gy} / \mathrm{min}$. The uncertainty in all delivered doses was estimated to be $1.0 \%$ of the dose (coverage factor $k=1.96$ ). Charged particle irradiations were performed using a ${ }^{14} \mathrm{~N}^{7+}$ particle beam accelerated by the Gustaf Werner Cyclotron located at the The Svedberg Laboratory, TSL, Uppsala University, Sweden. The beam energy was calculated by determining the depth-dose distribution measured stepwise by an ionisation chamber submerged at increasing depths in a water tank (resolution in the measured depth-dose distribution was estimated to $5 \mu \mathrm{m}$ ). The maximum absorbed dose was measured at 3.05 
$\mathrm{mm}$ depth in water and the beam energy could therefore be calculated to $\mathrm{E} \approx 33.5 \mathrm{MeV} / \mathrm{u}$ or (including rest mass of nucleus) $\mathrm{E} \approx 469 \mathrm{MeV}$. Tablets irradiated with the ${ }^{14} \mathrm{~N}^{7^{+}}$- particle beam were placed in a custom made sample holder made of PMMA and irradiated with the flat side facing the beam as indicated in figure 1 . The beam width, $20 \mathrm{~mm}$, was much larger than the diameter of the tablet ensuring a homogenous irradiation of the flat tablet side facing the beam.

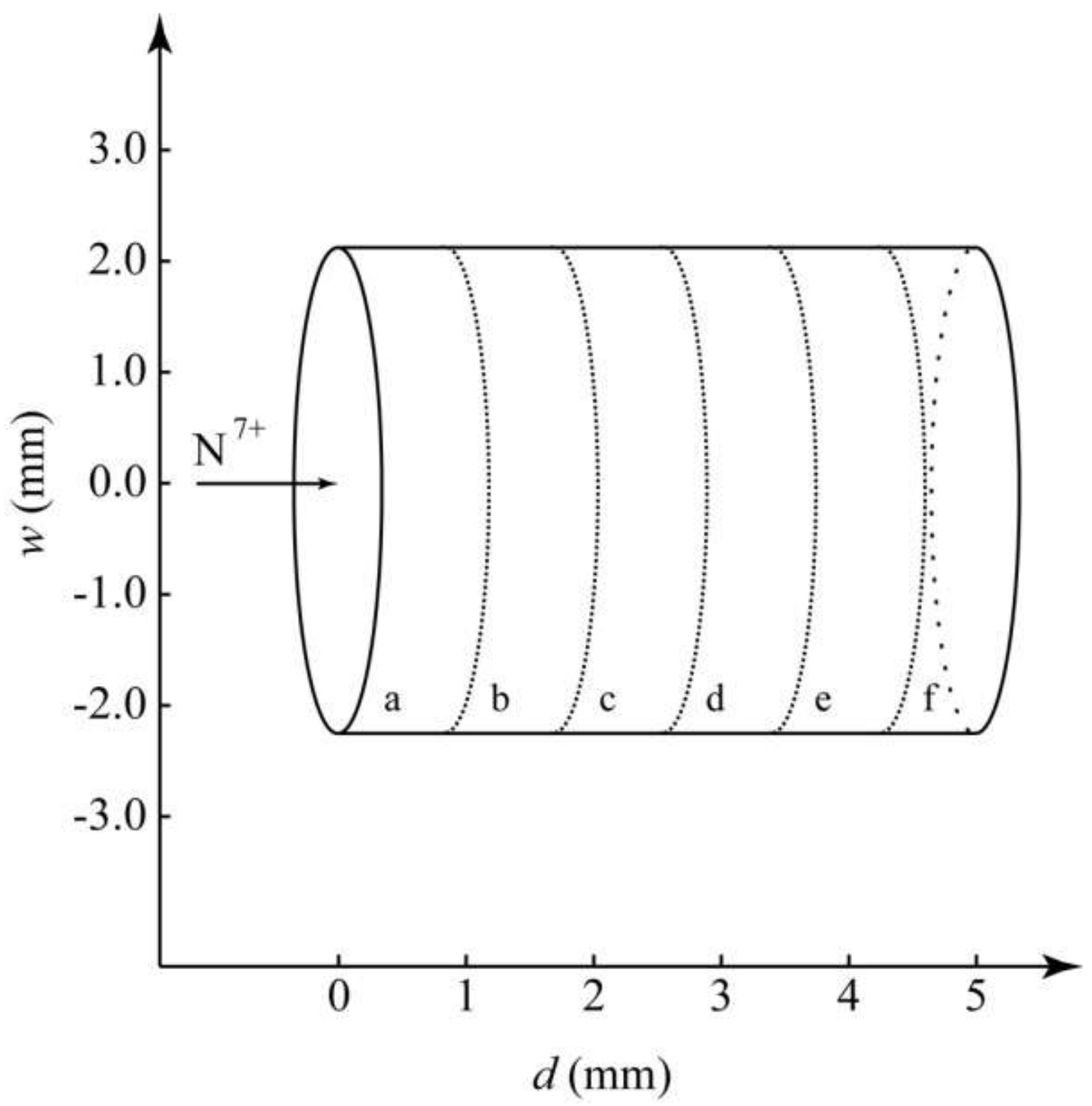

Figure 1. Potassium dithionate tablets were irradiated with the flat side facing the beam. The figure also shows preparation of slices a to $f$ at various tablet depths. 
2.3. Estimation of the mass collision stopping power in photon irradiated potassium dithionate

The mass collision stopping power, $\frac{S_{c o l l}}{\rho}$, is related to the linear energy transfer, $L_{\Delta}$, by a certain cut-off value $\Delta$ introduced to compensate for escaping $\delta$-particles in a small object or thin foil (ICRU 1998). In the following of this article $\Delta$ was chosen to equal the maximum particle energy, $\Delta=E_{\max }$, so that the linear energy transfer would be equal to the mass collision stopping power, $L_{\Delta}=\frac{S_{\text {coll }}}{\rho}$ for simplified calculations. Mass collision stopping power $\left(\frac{S_{\text {coll }}}{\rho}\right)$ in potassium dithionate irradiated with 1.75 MeV photons (mean energy of the $6 \mathrm{MV}$ linear accelerator) can be estimated to $\frac{S_{\text {coll }}}{\rho} \approx 1.57 \mathrm{MeV} \cdot \mathrm{cm}^{2} \cdot \mathrm{g}^{-1}$ using tabulated values (ICRU 1984).

2.4. Estimation of mass collision stopping power in $\mathrm{N}^{7+}$ irradiated potassium dithionate The distribution of the absorbed dose and mass collision stopping power in potassium dithionate dosimeters following irradiation with the described $\mathrm{N}^{7+}$-particle beam was simulated by means of the Monte Carlo code SRIM 2008 (Ziegler and Biersack 2008). The distribution of the mass collision stopping power in water was also simulated using the same method for comparison. Simulations are shown in figure 2. The figure also shows how the tablets were sliced for preparation of samples at various tablet depths (further discussed in section 2.5). Monte Carlo simulations of the particle range in water $(\mathrm{d}=3.03 \mathrm{~mm})$ agreed well with measurement $(\mathrm{d}=3.05 \mathrm{~mm})$ suggesting that the simulation protocol was reliable. Simulation of the particle range in potassium dithionate gave $\mathrm{d}=1.85 \mathrm{~mm}$ which agrees well with the particle range measured in potassium dithionate using EPR imaging (EPRI) (Gustafsson et al. 2008b). Mean absorbed dose, $\overline{D_{P D T}}$ (Gy), and mean mass collision 
stopping power, $\frac{\overline{S_{\text {coll }}}}{\rho}\left(\mathrm{MeV} \cdot \mathrm{cm}^{2} \cdot \mathrm{g}^{-1}\right)$, were calculated for each tablet slice (see section 2.5 and figure 1) for all $\mathrm{N}^{7+}$ irradiated tablets. Calculations gave $\overline{D_{P D T}}=\mathrm{o}$ Gy for all tablet slices $\mathrm{d}$, e and $\mathrm{f}$ (see section 2.5 and figure 1) and these slices are therefore omitted in the following.

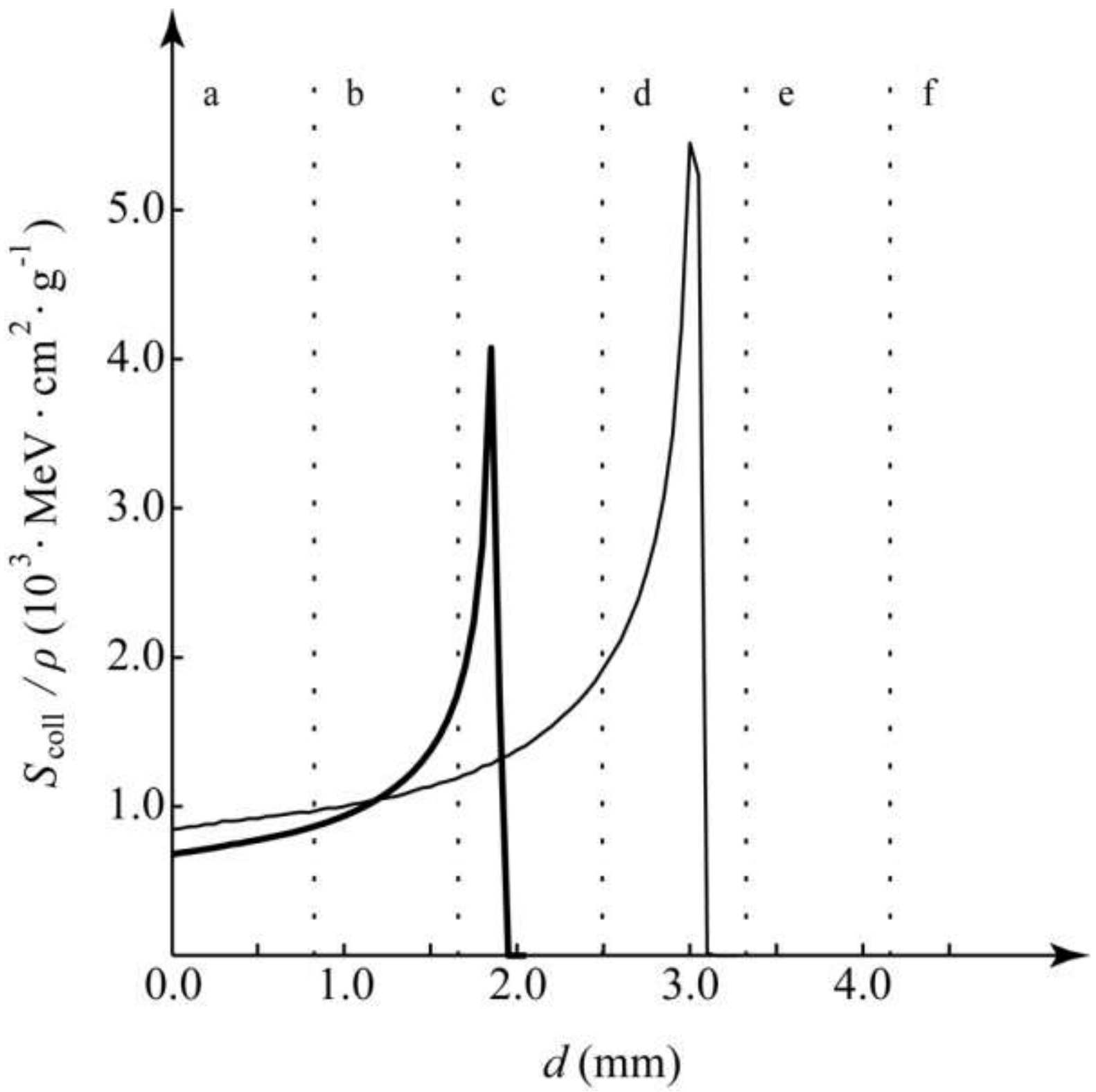

Figure 2. Monte Carlo simulation of the mass collision stopping power as a function of penetration depth in water (thin line) and potassium dithionate (bold line) following irradiation with a $\mathrm{N}^{7+}$ particle beam $(\mathrm{E}=469 \mathrm{MeV})$. Dashed lines indicate tablet slices a $-\mathrm{f}$.

\subsection{EPR measurements}

EPR measurements were performed using a BRUKER E580 ELEXSYS EPR spectrometer equipped with the standard cavity 4102 ST. All measurements were performed at $295 \mathrm{~K}$ 
using $0.1 \mathrm{mT}$ modulation amplitude, $100 \mathrm{kHz}$ modulation frequency, $20 \mathrm{~ms}$ time constant, $5 * 42$ seconds sweep, 1024 measurement points distributed over $3 \mathrm{mT}$. The microwave power was varied in the range of $0.1 \mathrm{~mW}$ to $200 \mathrm{~mW}$.

Tablets which had been irradiated with the $\mathrm{N}^{7+}$ - particle beam were sliced into six pieces as indicated in figure 1 . The uncertainty in tablet slicing was estimated to $\pm 0.2 \mathrm{~mm}$. Slices thus covered were: a: $0.0 \mathrm{~mm}-(0.8 \pm 0.2) \mathrm{mm}, \mathrm{b}:(0.8 \pm 0.2) \mathrm{mm}-(1.7 \pm 0.2) \mathrm{mm}, \mathrm{c}:(1.7 \pm 0.2)$ $\mathrm{mm}-(2.5 \pm 0.2) \mathrm{mm}, \mathrm{d}:(2.5 \pm 0.2) \mathrm{mm}-(3.3 \pm 0.2) \mathrm{mm}, \mathrm{e}:(3.3 \pm 0.2) \mathrm{mm}-(4.2 \pm 0.2)$ $\mathrm{mm}$ and $\mathrm{f}:(4.2 \pm 0.2) \mathrm{mm}$ to $5.0 \mathrm{~mm}$. Slices were gently crushed in a mortar and transferred to EPR sample tubes (Heraeus suprasil, outer diameter $3 \mathrm{~mm}$ ). The mass of each sample was $13 \pm 1 \mathrm{mg}$. Photon irradiated tablets were measured with the whole tablet inserted in a WILMAD EPR sample tube Q-5M-6M-O-200m-FB (inner diameter $5 \mathrm{~mm}$, flat bottom).

The intensities of peaks $R_{1}$ and $R_{2}$ were measured in arbitrary units as indicated in figure 3 .

\section{Results}

3.1. EPR spectrum of potassium dithionate

Typical spectra of photon irradiated potassium dithionate and potassium dithionate irradiated in $\mathrm{N}^{7+}$ are shown in figure 3 ( $4 \mathrm{~mW}$ applied microwave power). No EPR signal was detected in potassium dithionate prior to irradiation.

The relative intensity of $R_{1}$ and $R_{2}$ varied with microwave power. $R_{1}$ reached its maximum intensity at $2 \mathrm{~mW}$ and $\mathrm{R}_{2}$ reached its maximum at $8 \mathrm{~mW}$. An applied microwave power of $4 \mathrm{~mW}$ was chosen for all further experiments as an acceptable compromise between microwave saturation properties and measurement sensitivity.

EPR spectra from three tablet slices from regions of increasing depths in a $\mathrm{N}^{7+}$ irradiated potassium dithionate tablet are presented in figure 4 (the signal intensities are normalised to equal $R_{1}$ intensities by division with the measured $R_{1}$ in each spectrum to allow for simple comparison of EPR spectral shape in the figure). 


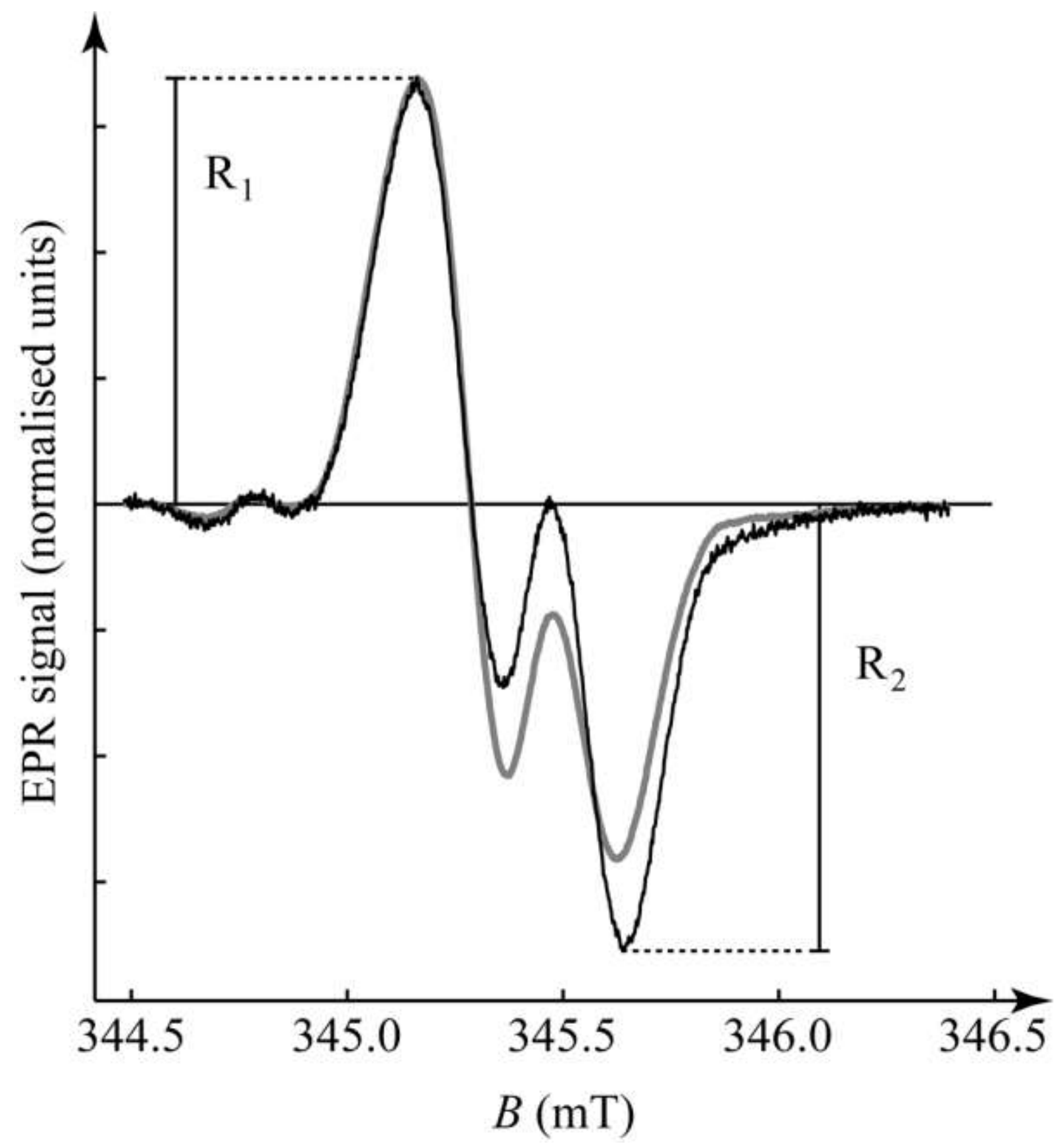

Figure 3. EPR spectrum of potassium dithionate irradiated with $\mathrm{N}^{6+}$ ions (black line) and photon irradiated potassium dithionate (bold grey line). Measurements were performed using an applied microwave power of $4 \mathrm{~mW}$. The EPR spectra are normalised to equal $\mathrm{R}_{1}$ intensities. Notice the differences in EPR spectral shape for the two samples. 


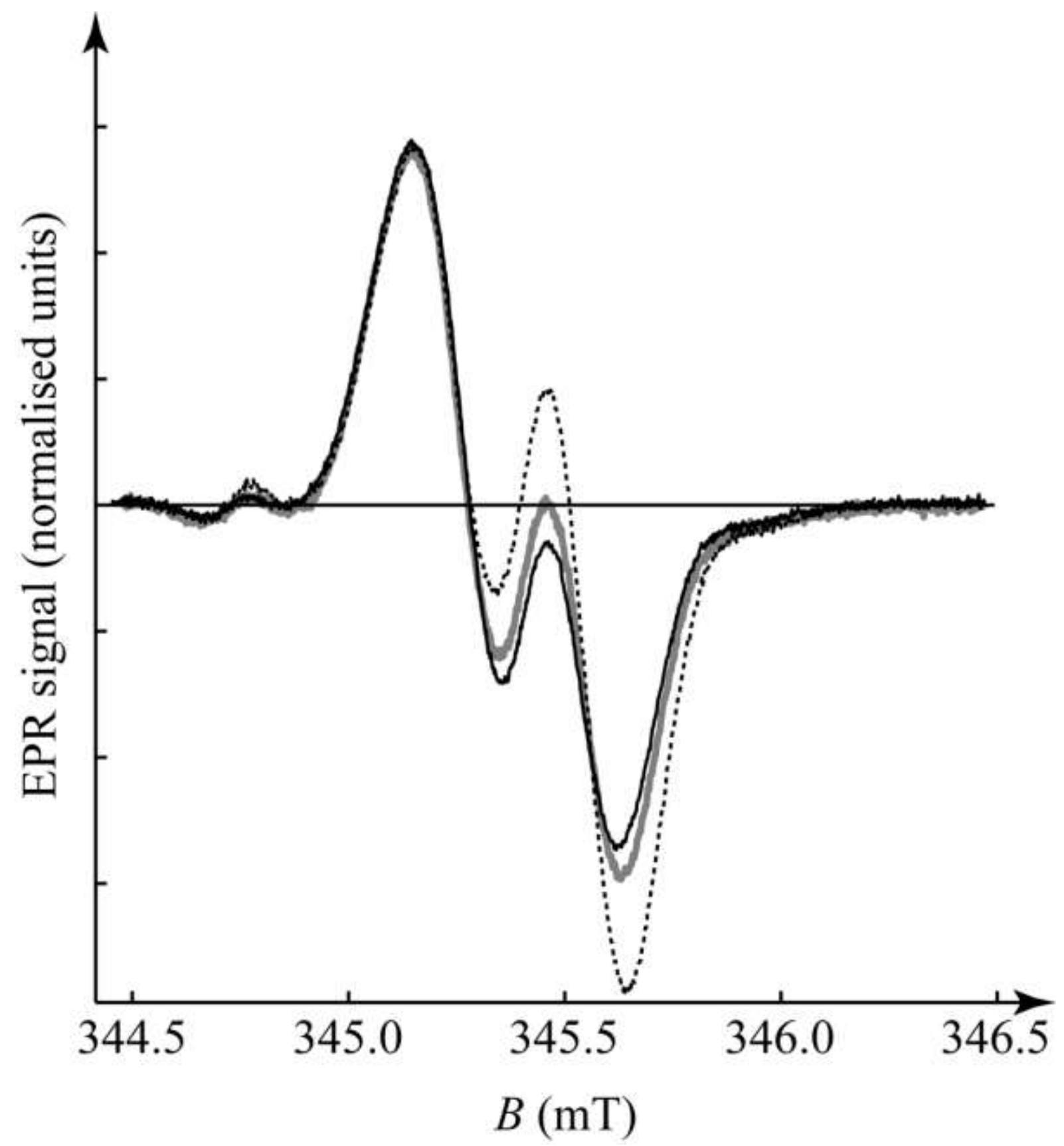

Figure 4. EPR spectra (4 mW applied microwave power) from three tablet slices at regions of increasing depths in a $\mathrm{N}^{7+}$ irradiated potassium dithionate tablet. Spectra are normalised to equal $\mathrm{R}_{1}$ intensities. Black line - slice a $(0.0 \mathrm{~mm}-(0.8 \pm 0.2) \mathrm{mm})$, bold grey line - slice $\mathrm{b}$ $((0.8 \pm 0.2) \mathrm{mm}-(1.7 \pm 0.2) \mathrm{mm})$, dashed black line - slice $\mathrm{c}((1.7 \pm 0.2) \mathrm{mm}-(2.5 \pm 0.2)$ $\mathrm{mm})$. Slices $\mathrm{d}$, e and $\mathrm{f}$ gave no EPR signal and are therefore omitted in the figure.

3.2. $R_{1} / R_{2}$ ratio for different beam qualities (different beam LET)

The intensities of peaks $R_{1}$ and $R_{2}$ (in arbitrary units as indicated in figure 3 ) and the total mass normalised EPR signal intensity $\left(l_{w}^{n o r m}\right)$ were measured for all photon irradiated tablets and for all slices of $\mathrm{N}^{7^{+}}$- irradiated tablets. Figure 5 shows measured $\mathrm{R}_{1} / \mathrm{R}_{2}$-ratio as a 
function of calculated mean mass collision stopping power, $\frac{\overline{S_{\text {coll }}}}{\rho}\left(\mathrm{MeV} \cdot \mathrm{cm}^{2} \cdot \mathrm{g}^{-1}\right)$ for all samples. The line indicates an exponential decay $\left(y=a+b \cdot e^{-c \cdot x}\right)$ fitted to the measured data using the least squares method. Mean values $\left(\overline{R_{1} / R_{2}}\right)$ and the range in the measured $R_{1}$ / $R_{2}$ ratio in potassium dithionate irradiated with photons and for increasing depth in $\mathrm{N}^{7^{+}}$irradiated samples are displayed in table I.

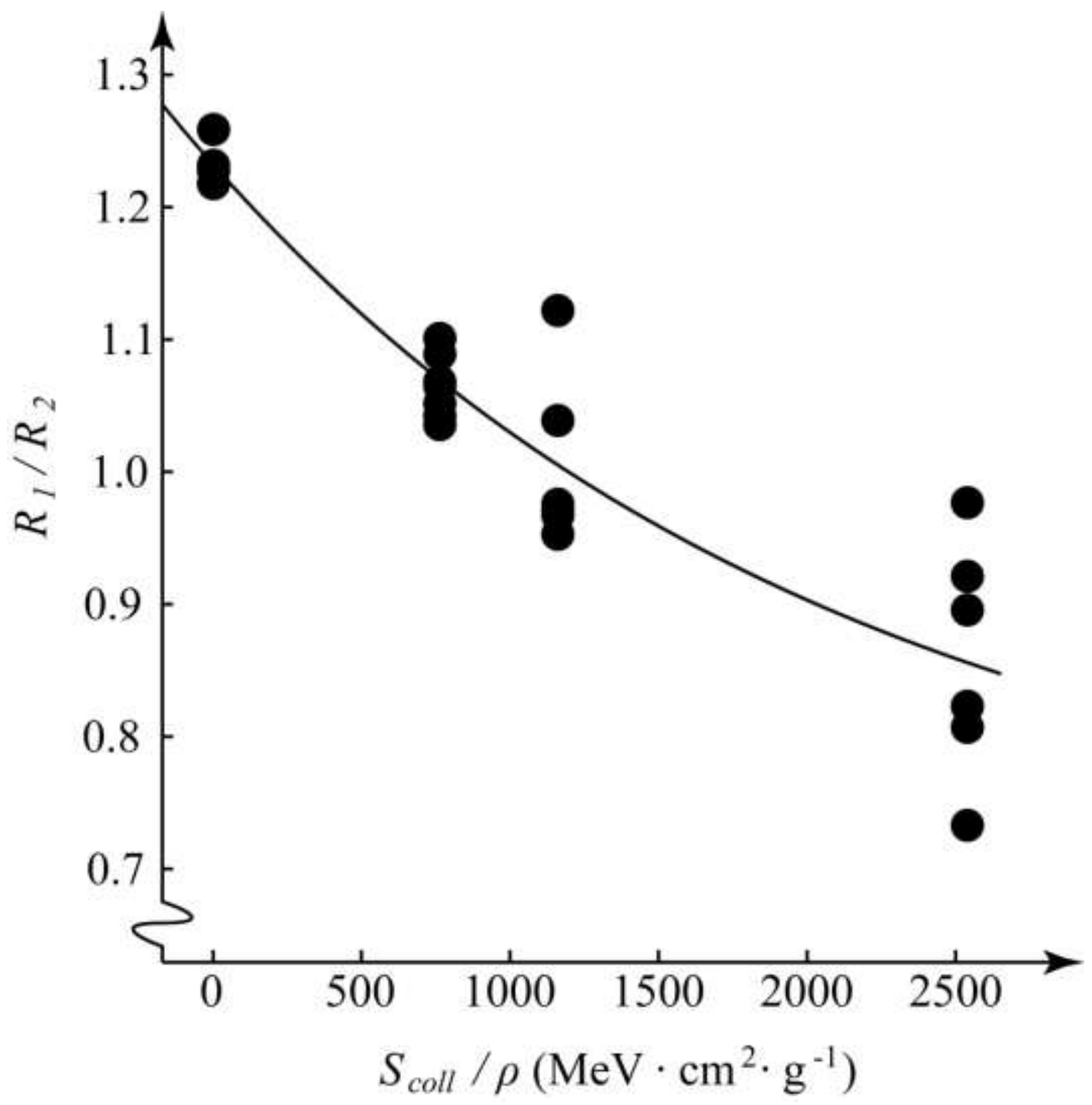

Figure 5. Measured $R_{1} / R_{2}$-ratio as a function of calculated mean mass collision stopping power, $\frac{\overline{S_{\text {coll }}}}{\rho}\left(\mathrm{MeV} \cdot \mathrm{cm}^{2} \cdot \mathrm{g}^{-1}\right)$ for all samples. The line indicates an exponential decay $\left(y=a+b \cdot e^{-c \cdot x}\right.$ ) fitted to the measured data using the least squares method (y - measured $\mathrm{R}_{1} / \mathrm{R}_{2}$-ratio, $\mathrm{x}$ - calculated mean mass collision stopping power, $\frac{\overline{S_{\text {coll }}}}{\rho}\left(\mathrm{MeV} \cdot \mathrm{cm}^{2} \cdot \mathrm{g}^{-1}\right)$, a constant (dimension-less), b- constant (dimension-less) and $\mathrm{c}-$ constant $\left(\mathrm{MeV}^{-1} \cdot \mathrm{cm}^{-2} \cdot \mathrm{g}\right)$ ). 


\section{TABLE I}

Mean values $\left(\overline{R_{1} / R_{2}}\right)$ and the range in the measured $R_{1} / R_{2}$ ratio in potassium dithionate irradiated with photons and for increasing depth in $\mathrm{N}^{7+}$ - irradiated samples.

\begin{tabular}{|c|c|c|c|}
\hline Beam quality & Slice & $\overline{R_{1} / R_{2}}$ & Range in measured $\mathrm{R}_{1} / \mathrm{R}_{2}$ \\
\hline $6 \mathrm{MV}$ & - & 1.24 & $1.22-1.26$ \\
\hline $\mathrm{N}^{7+}$ & $\mathrm{a}$ & 1.07 & $1.04-1.10$ \\
\hline $\mathrm{N}^{7+}$ & $\mathrm{b}$ & 1.00 & $0.95-1.12$ \\
\hline $\mathrm{N}^{7+}$ & $\mathrm{c}$ & 0.86 & $0.73-0.98$ \\
\hline
\end{tabular}




\section{Discussion}

The doublet in the EPR spectra of irradiated potassium dithionate is attributed to two signals with different microwave power saturation properties as shown earlier (Gustafsson et al 2008b). The two signals are assigned to two non-equivalent $\mathrm{SO}_{3}^{-}$-radicals due to the irradiation induced cleavage of the S-S bond with similarities to the radical formation observed in irradiated caesium dithionate (Mahgoub et al. 1983, 1994) and irradiated barium dithionate (Baran et al. 2006, 2007). The two $\mathrm{SO}_{3}{ }^{-}$radicals in $\mathrm{K}_{2} \mathrm{~S}_{2} \mathrm{O}_{6}$ are probably located in different sites in the crystal lattice, and it is not unreasonable that they therefore have different microwave power saturation properties with $R_{1}$ being more easily saturated than $\mathrm{R}_{2}$. Similar saturation properties were observed for the two signals present in photon irradiated barium dithionate by Baran et al. (2006).

The LET from particle beams is increasing with increasing penetration depth as indicated in figure 2. As shown in figure 3 - 5 and table I there was a clear dependence of the $R_{1} / R_{2}$ - ratio on the beam quality. This result was therefore in accordance with previous measurements by EPR imaging (Gustafsson et al. 2008b). The measured data could be reasonably modelled by an exponential dependence between the $R_{1} / R_{2}$ - ratio in the potassium dithionate EPR spectrum and beam quality, indicating a possible relation. The relatively large spread in the measured $R_{1} / R_{2}$ - ratios could be explained by the comparatively large uncertainty $( \pm 0.2$ $\mathrm{mm}$ ) in the tablet depths covered by each slice. This uncertainty in the tablet depths covered by each slice give large variations in the mass collision stopping power as seen in figure 2 and will therefore give uncertainties in both the absorbed dose in each slice as well as uncertainties in the LET $\left(L_{\Delta}\right)$.

Without using sophisticated methods like those described by Malinen et al. (2006) and Waldeland et al. (2010b) differences in line width in EPR spectra from samples irradiated with different beam qualities were not detectable. This might be explained by the fact that the increase in line width due to higher ionisation density is small. 


\section{CONCLUSIONS}

The current study indicates that the intensity ratio $R_{1} / R_{2}$ of two signals in EPR spectra of potassium dithionate can be used to estimate the beam quality (LET) in addition to determinations of absorbed dose using the peak-to-peak amplitude $\left(R_{1}+R_{2}\right)$. Potassium dithionate may therefore be a promising EPR dosimeter material for measurements of absorbed doses in high-LET radiation fields. The ratio of $R_{1} / R_{2}$ could also be used for the calculation of a correction factor to compensate for the differences in signal intensity which are expected if irradiation of calibration tablets and dosimeters are performed in beams with different LET. The aim of further investigations will be to deduce a calibration table from the LET dependent spectrum changes described in the present work. This will allow high precision measurements of absorbed dose in high-LET beams without the need for calibrating dosimeters in exactly the same beam LET using potassium dithionate EPR dosimetry. Important for future measurements will also be to thoroughly study the long term stability of the radiation induced EPR signal including the stability of the $R_{1} / R_{2}$ - ratio with respect to time. 


\section{ACKNOWLEDGMENTS}

The authors would like to thank Ass Professor. B Stenerlöw and Dr Torbjörn Hartmann for valuable information about the beam characterization and help with irradiations at TSL and Mr. Hilding Karlsson (Department of Material Chemistry, Uppsala University, Sweden) for his synthesis of potassium dithionate. Private communication with Professor E Sagstuen is acknowledged. This work was supported by grants from The Swedish Cancer Society no. 4276-Bo5-07XBC. 


\section{REFERENCES}

Adolfsson, E., Alm Carlsson, G., Grindborg, J.-E., Gustafsson, H., Lund, E., Carlsson

Tedgren, Å. 2010. Response of lithium formate EPR dosimeters at photon energies relevant to the dosimetry of brachytherapy. Med. Phys. 37, 4946-4959.

Antonovic, L., Gustafsson, H., Alm Carlsson, G., Carlsson Tedgren, Å., 2009. Evaluation of a lithium formate EPR dosimetry system for dose measurements around 192Ir brachytherapy sources. Med. Phys. 36, 2236-2247.

Baran, M.P., Bugay, O.A., Kolesnik, S.P., Kaksimenko, V.M., Teslenko, V.V., Petrenko, T.L., Desrosiers, M.F., 2006. Barium dithionate as an EPR dosemeter. Radiat. Prot. Dosim. 120, 202-204.

Baran, M.P., Mazin, M.O., Maksimenko, V.M., 2007. EPR studies of radiation-induced centers in crystalline barium dithionate dihydrate. Ukr. J. Phys. 7, 676-80.

Baran, N.P., Maksimenko, V.M., Teslenko, V.V., Bugay, A.A., 2008. EPR spectra of $\gamma^{-}$ irradiated hydrated barium dithionate single crystals. Journal of Applied Spectroscopy 75, 15 $-20$.

Bogushevich, S.E., Ugolev, I.I., 2000. Inorganic EPR dosimeter for medical radiology. Appl. Radiat. Isot. 52, 1217-19.

Brauer, G., 1954. Handbuch der preparativen anorganische Chemie. F. Enke, Stuttgart.

Ciesielski, B., Wielopolski, L., 1994. The effects of dose and radiation quality on the shape and power saturation of the EPR signal in alanine. Radiat. Res. 140, 105-111. 
Ciesielski, B., Stuglik, Z., Wielopolski, L., Zvara, I., 1998. The effect of high-linear energy transfer ion on the electron paramagnetic resonance signal induced in alanine. Radiat. Res. 150, 469-474.

Danilczuk, M., Gustafsson, H., Sastry, M.D., Lund, E., Lund, A., 2008. Ammonium Dithionate - a New Material for Highly Sensitive EPR Dosimetry. Spectrochim. Acta Part A $69,18-211$.

Gustafsson, H., Olsson, S., Lund, A., Lund, E., 2004. Ammonium formate, a compound for sensitive EPR dosimetry. Radiat. Res. 161, 464-470.

Gustafsson, H., Danilczuk, M., Sastry, M.D., Lund, A., Lund, E., 2005. Enhanced sensitivity of lithium dithionates doped with rhodium and nickel for EPR dosimetry. Spectrochim. Acta Part A 62, 614-620.

Gustafsson, H., Lund, E., Olsson, S., 2008a. Lithium formate EPR dosimetry for verifications of planned dose distributions prior to intensity modulated radiation therapy. Physics in Medicine and Biology 53, 4667-4682.

Gustafsson, H., Kruczala, K., Lund, E., Schlick, S., 2008b. Visualization of Dose Distribution and Linear Energy Transfer by 1D and 2D Spectral-Spatial ESR Imaging: A Potassium Dithionate Dosimeter Irradiated with C6+ and N7+ Ions. J. Phys. Chem. B 112, 8437-8442.

Hansen, J.W., Olsen, K.J., 1989. Predicting decay in free-radical concentration in L-aalanine following high-LET radiation exposures. Appl. Radiat. Isot. 40, 935-39. 
ICRU, 1984. Stopping powers for electrons and positrons. ICRU Report 37, Bethesda, MD: ICRU.

ICRU, 1998. Fundamental Quantities and Units for Ionizing Radiation. ICRU Report 60, Bethesda, MD: ICRU.

Lund, A., Olsson, S., Bonora, M., Lund, E., Gustafsson, H. 2002. New materials for ESR dosimetry. Spectroc. Acta Part. A. 58, 1301-1311.

Mahgoub, A.S.M., Lund, A., Liminga, R., 1983. Molecular model of radiation damage in Cs2S2O6 crystals at room temperature. Radiat. Phys. Chem. 21, 527-532.

Magoub, A.S., Lund, A., Lindgren, M., 1994. An ENDOR study of 133 Cs hyperfine couplings with $\mathrm{SO}_{3}{ }^{-}$radicals on X-irradiated $\mathrm{Cs}_{2} \mathrm{~S}_{2} \mathrm{O}_{6}$ piezoelectric single crystals. J. Mater. Chem. 4, 223-227.

Malinen, E., Waldeland, E., Hole, E.O., Sagstuen, E., 2006. LET effects following neutron irradiation of lithium formate EPR dosimeters. Spectrochim. Acta Part A 63, 861-869.

Marrale, M., Brai, M., Barbon, A., Brustolon, M., 2009. Analysis of the spatial distribution of free radicals in ammonium tartrate by pulse EPR techniques. Radiat. Res. 171, 349-359.

Norman, A., 1967. Thermal spike effects in heavy-ion tracks. Radiat. Res. Suppl. 7, 33-37.

Olsson, S., Lund, E., Lund, A., 2000. Development of ammonium tartrate as an ESR dosimeter material for clinical purposes. Appl. Radiat. Isot. 52, 1235-1241. 
Rakvin, B., Maltar-Strmečki, N., Nakagawa, K., 2007. Pulsed EPR study of low-dose irradiation effects in L-alanine irradiated with $\gamma$-rays, $\mathrm{Ne}$ and $\mathrm{Si}$ ion beams. Radiation Measurements 42, 1469-1474.

Regulla, D. F., Deffner, U., 1982. Dosimetry by ESR spectroscopy of alanine. Appl. Radiat. Isot. $33,1101-1114$.

Sagstuen, E., Hole, E.O., Haugedal, S.R., Nelson, W.H., 1997. Alanine Radicals: Structure Determination by EPR and ENDOR of Single Crystals X-Irradiated at 295 K. J. Phys. Chem. A 101, 9763-72.

Waldeland, E., Olaug Hole, E., Sagstuen, E., Malinen, E., 2010a. The energy dependence of lithium formate and alanine EPR dosimeters for medium energy x rays. Med. Phys. 37, 35693575 .

Waldeland, E., Olaug Hole, E., Stenerlöw, B., Grusell, E., Sagstuen, E., Malinen, E. 2010b. Radical formation in lithium formate EPR dosimeters after irradiation with protons and nitrogen ions. Rad. Res. 174, 251-257.

Ziegler, J.F., Biersack, J.P., 2008. SRIM-The stopping and range of ions in matter. Version: SRIM-2008.03.; http://www.srim.org. 